\title{
FROM PATHOGENESIS TO THERAPY OF COVID-19
}

\author{
Stanislav Yanev ${ }^{*}$ and George N. Chaldakov ${ }^{2}$ \\ ${ }^{1}$ Laboratory of Drug Toxicology, Institute of Neurobiology, Bulgarian Academy of Sciences, Sofia, \\ Bulgaria, ${ }^{2}$ Department of Anatomy and Cell Biology, Medical University, Varna, Bulgaria
}

The world is facing the pandemic of a new coronavirus (SARS-CoV-2) leading to the development of coronavirus disease (COVID-19). In effect, the scientific potential in the field becoming the cutting-edge of biomedical research. It is in a big race to test the available pharmacologic resource of registered antiviral drugs and to discover of novel pharmaceuticals, nutraceuticals and biologicals (such as vaccines, gene and stem cell therapy, and recombinant proteins produced biotechnologically). We argue that the knowledge of (i) angiotensin converting enzyme 2 (ACE2) receptor, (ii) viral S-glycoprotein ligand, and (iii) cellular proteases, required for the entry of Cov-2 into the target cell, may provide novel therapeutic approaches for COVID-19. Finally, we reason the described approaches could lead to the identification of better drugs for COVID-19 and post-COVID-19 syndrome.

Biomed Rev 2020; 31: 125-133

Keywords: SARS-CoV-2, COVID-19, S-glycoproteins, ACE, ACE2, antiviral drugs, cytokine storm

Received 14 December 2020, revised 22 December 2020, accepted 22 December 2020.

*Correspondence to: Dr Stanislav Yanev, Laboratory of Drug Toxicology, Institute of Neurobiology, Bulgarian Academy of Sciences, BG-113 Sofia, Bulgaria

E-mail: stanislav_yanev@yahoo.com 


\section{INTRODUCTION}

Indeed, the Earth is facing the pandemic of severe acute respiratory syndrome induced by coronavirus-2 (SARS$\mathrm{CoV}-2$, hereinafter $\mathrm{CoV}-2$ ) leading to the development of coronavirus disease (COVID-19), the event of the year MMXX picturizing below.

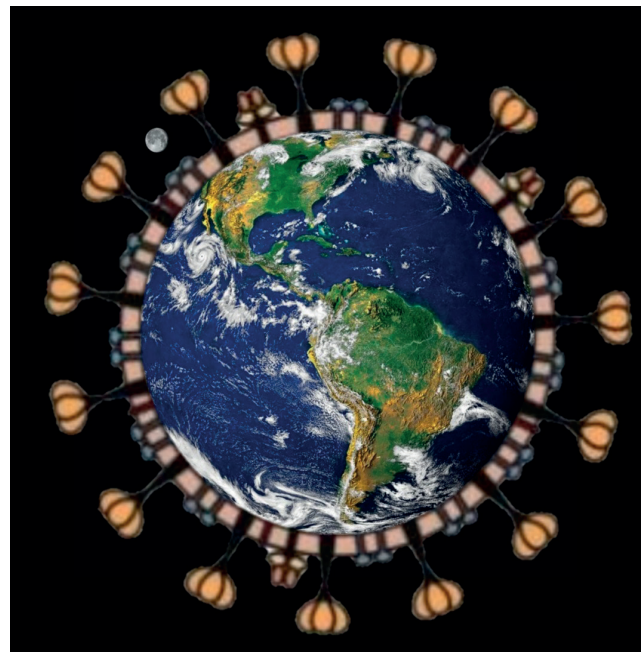

Credit for Nikifor N. Chaldakov.

Since the end of 2019 many clinical trials have been performing aimed at the evaluation of effectiveness of various therapies for COVD-19. Most of them being with antiviral drugs (antivirals) that have been applied for the therapy of other infections $(1,2)$. Herein, we Dance Round the pathogenesis and therapy of COVD-19.

\section{FIGHTING VIRAL INFECTION BY THE BLOCKAGE OF COV-2 ENTRY INTO THE CELL}

Viruses enter cells by two main ways: (i) receptor-mediated endocytosis (RME), and (ii) receptor-mediated virus-cell fusion (receptor-mediated fusion, RMF) (3, 4). In 1990 one of us (GNC) published his hypothesis of inhibition RME of viruses as an opportunity for antiviral therapy, including for acquired immunodeficiency syndrome (AIDS) (5). A schematic portrait of CoV-2 is presented in Figure 1.

Highly innovative methods of molecular biology and virology allowed scientists to very quickly identify the molecular architecture of CoV-2 (Fig. 2).

The CoV-2 is enveloped, single-stranded RNA betacoronavirus. Like Middle East Respiratory Syndrome coronavirus (MERS-CoV), the genome of CoV-2 encodes (i) several nonstructural proteins (e.g., chimotrypsin-

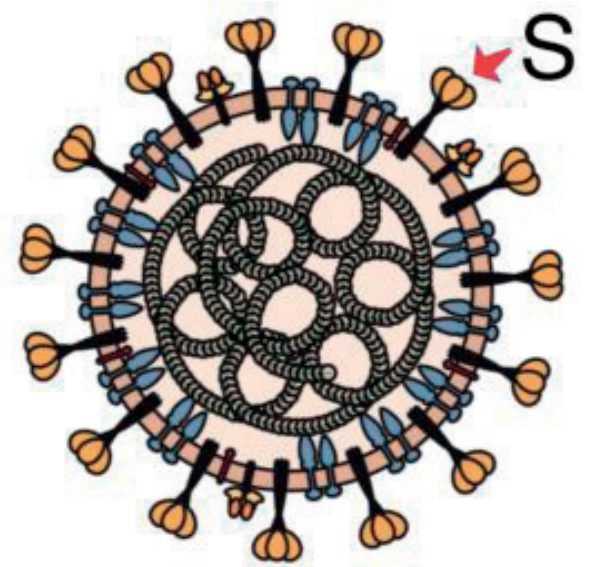

Figure 1. Scheme illustrating the new coronavirus (SARS$\mathrm{CoV}-2)$, a spherical particle sized 80-100 $\mathrm{nm}$ in diameter. Located in the viral membrane are transmembrane spikes (S) (one of them, red arrow) composed of glycoproteins; they play a pivotal role in $\mathrm{CoV}$-2 entry into the target cell. S-glycoproteins must be processed (cleaved) by the cellular protease furin (S-glycoproteins have a furin cleavage site) aimed at virus fusion with the cell surface membrane leading to the internalization of virus into the cell. Therefore, inhibitors offurin and/or others $\mathrm{CoV}-2$ related proteases may have antiviral effects (6; for other viruses including human immunodeficiency virus - HIV, see 7).

like protease, papain-like protease, helicase, and RNAdependent RNA polymerase ), and (ii) structural proteins (e.g., S-glycoproteins). The four non-structural proteins are key enzymes for viral life cycle, and S-glycoproteins are indispensable for interaction with cell receptors over the time of viral entry. Therefore, these five proteins (i, ii) are suitable as targets for the development of antivirals against the invader CoV-2. They are involved in all steps of viral life in the host cell: entrance into the cell, release of viral envelope, replication of viral RNA, exit of the new-born viruses from the infected cell, followed by dissemination to other cells.

\section{I.1. Receptor-mediated CoV-2 entrance into the target cell}

The virus-cell interaction is a receptor-mediated process, leading to the viral fusion with the cell surface membrane (plasmalemma) followed by the entrance of virus into the cell. Through receptor binding domain (RBD) of S-glycoprotein, $\mathrm{CoV}-2$ binds to selective domains of receptors localized within the cellular plasmalemma (4). The presence and degree of 


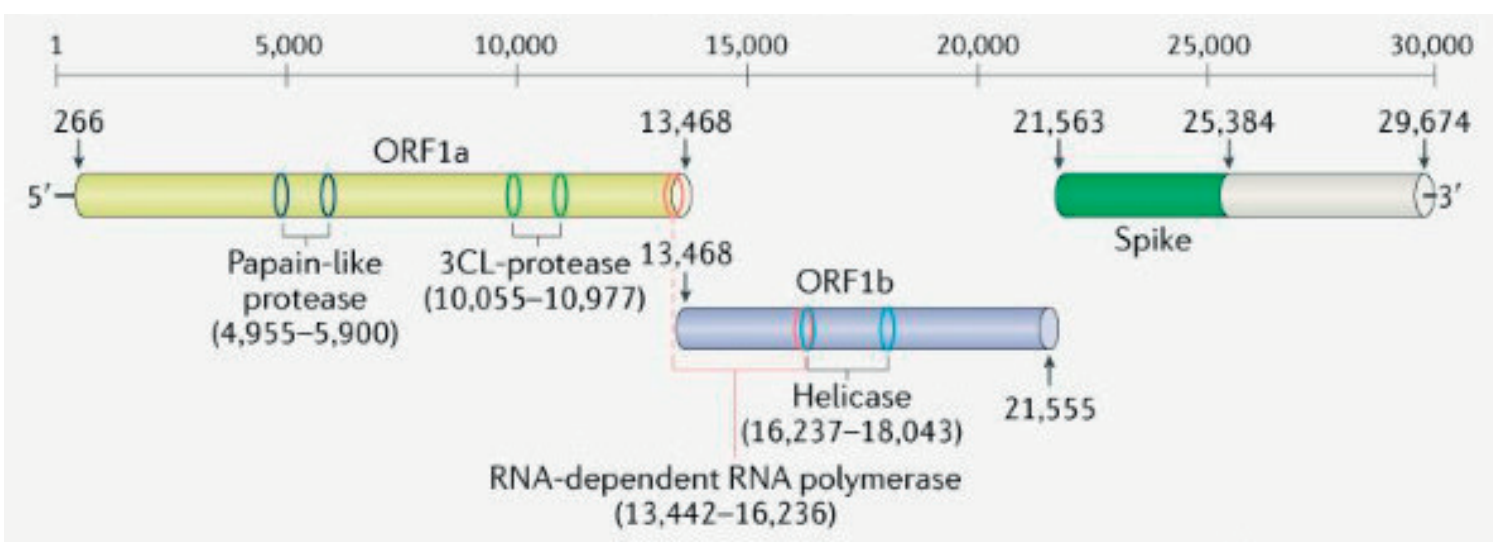

Figure 2. Genomic organization of SARS-CoV-2. From: (8).

expression of receptors largely predetermined the specificity of pathological changes after viral attack in certain cells, tissues and organs.

Target cells for respiratory viruses are different epithelial cells of the oral cavity, bronchi and alveoli. One of the CoV-2 receptors is angiotensin converting enzyme 2 (ACE2), a singlepass transmembrane protein of pneumocytes (alveolocytes ) type II secreting the pulmonary surfactant (Fig. 3). Another receptor for CoV-2 is CD147 (basigin) - Meplazumab, an anti-CD147 monoclonal antibody, has recently been applied to COVID-19 patients (see Dance Round by Yanev and by Chaldakov et al in this volume of Biomedical Reviews).

\section{I.2. Physiology and pathology of ACE2}

Analysis of the Human Protein Atlas Database shows that pulmonary cells expressing ACE2 are exceptional few, but at

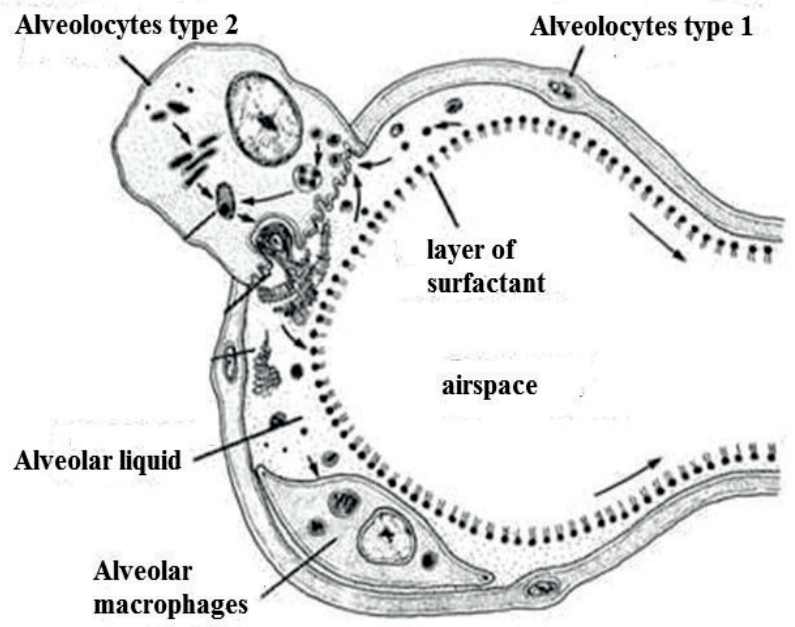

Figure 3. Scheme of pulmonary alveolus and its cells. the same time contain many other genes positively regulating viral reproduction and transmission. ACE 2 also presents in arterial and venous endothelial cells and arterial smooth muscle cells, in brain cells and epithelial cells of kidneys, testicles, gall bladder and brain neurons, thus the viral invasion can be happened not only in the lung (9). In the human cells, ACE2 is regulated by different genes which can increase or decrease virus replication, suggesting that ACE2 regulatory genes might be promising therapeutic targets in COVID-19.

The enzyme ACE2 functions at the final stages regulating the peptides with important roles for cardiovascular, renal and respiratory systems. It is critically involved in the homeostasis of (i) angiotensin II (Ang II) (involved in vascular contraction, cell proliferation, and profibrotic and prothrombotic activity mediated by AT1 and AT2 receptors), and (ii) Ang-(1-7) (involved in vasodilatation and antiproliferative, antifibrotic and antithrombotic activity realized via interaction with MAS receptor, a member of the family of $G$ proteincoupled receptors). In effect, MAS receptor ligation by Ang-(1-7) opposes many of Ang II effects. Thus, MAS1 receptor agonists express similar therapeutic effects as Ang II receptor antagonists. The renin-angiotensin system (RAS) with possible impact sites to compensate for the effect of coronavirus is shown schematically in Figure 4.

Briefly, ACE2 is a transplasmalemmal protein whose ectodomain functions as an enzyme involved in Ang metabolism as well as a receptor for CoV-2 cellular entry. That is, ACE2 has a catalytic domain for Ang I and Ang II and a binding domain for coronavirus S-glycoproteins. Occupation of ACE2 by CoV-2 may disturb the balance of ACE-ACE2 functions that can be modified by different therapeutic approaches (see Fig. 4, also Yanev and Stoyanova in this volume of Biomedical Reviews). 


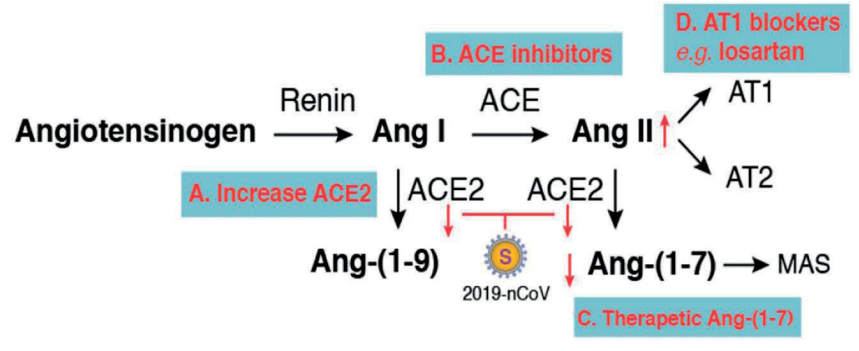

Figure 4. Based on the balance of renin-angiotensin system (RAS), potential therapeutic approaches for lung COVID-19 are depicted. Upon activation of the RAS cascade, the enzyme reninmetabolizes angiotensinogen to Ang I, which is converted to Ang II by ACE. Ang II through its receptors (AT1 and AT2) exerts local and systemic effects, such as vasoconstriction and stimulation of release of aldosterone. ACE2 functions as an antiregulatory enzyme to balance the responses initiated from the ACE. ACE 2 metabolizes Ang I and Ang II to Ang-(1-9) and Ang-(1-7). By binding to the MAS receptor, Ang-(1-7) antagonizes Ang II-mediated actions. From: (10).

The importance of ACE2 receptors for the realization of CoV-2 lung infection has been reported in recent review articles $(11,12)$. In a clinical study of patients with COVID-19, important correlates have been identified: Ang II circulating level is significantly increased and linearly linked with viral titer and lung damage. Moreover, the administration of Losartan, an Ang II receptor blocker, resulted in good symptomatic effects in COVID-19 patients (13). The expression level of ACE2 in different tissues is crucial for the symptoms of COVID-19. Preliminary data indicate the presence of significant differences in ACE2 expression in different tissues of patients from East Asian and European origin, higher expression and greater sensitivity to infection in the first group $(14,15)$. There is evidence that smoking induces ACE2 in the respiratory tract which suggests that smokers would have a higher susceptibility to CoV-2 infection (16).

\section{I.3. Blockage the entry of CoV-2 into the cell at the receptor level}

Chloroquine is a proven candidate for the modulation of viral cell entry and viral replication. This antimalarial drug turns out to have antiviral action. Chloroquine is lysosomotropic chemical that affects the viral infection by inhibiting the acidification of endosomes, membrane bound organelles of lysosomal cell apparatus, wherein act vacuolar $\mathrm{H}+$-ATPase
(17). This leads to an increase in the $\mathrm{pH}$ of the endosomes, which blocked (i) the dissociation of the virus from the ACE2 receptor, (ii) its release into the cytoplasm, and (iii) the viral replication and infection. Hence, chloroquine has been used for therapy of viral diseases dependent on endosomal acidic $\mathrm{pH}(18)$.

The homeostasis of endosomal $\mathrm{pH}$ - dependent proteases is indeed an important cellular phenomenon that deserves further research into pharmacotherapy of CoV-2 infection (19). Further, chloroquine's immunomodulatory properties synergistically increasing its antiviral effect (20). It has already been tested in 23 clinical trials in patients with pneumonia caused by CoV-2 (21); the first results were encouraging. It should be noted that for successful chloroquine therapy is important the time of its application. It would be more efficient and more slightly toxic in the initial phase of the development of infection (during the first 5-7 days). This is logical, given the type of its action in the first stages of the virus attack cellular entry and replication of CoV-2. Successful clinical outcomes have been observed after its combine application with the antibiotic Azithromycin applied to block the possible development of secondary bacterial infection.

\section{I.4. Cellular proteases}

Transmembrane protease serine 2 (TMPRSS 2) belongs to the family of serine proteases. This enzyme facilitates viral penetration into the cell. There are clinical trials for selective inhibition of TMPRSS 2 by Camostat mesylate (22).

Lopinavir and Ritonavir are protease inhibitors used to treat AIDS. Given that Cov-2 protease was found to be similar to that of HIV, this combination has already been tested with varying success in patients with COVID- 19.

\section{BLOCK OF VIRAL RNA REPLICATION}

Remdesivir is a broad-spectrum antiviral drug, still being investigating in COVID-19 patients. It has been used against Ebola and coronaviruses causing SARS and MERS. Remdesivir is an adenosine analog included in the viral RNA chain and thus blocks its replication (20).

Favipiravir is a selective inhibitor of viral RNA-dependent RNA polymerase. It is a prodrug that is metabolized to its active form, favipiravir-ribofuranosyl-5'-triphosphate (favipiravir-RTP), from human hypoxanthine guanine phosphoribosyltransferase (HGPRT) (23).

Altogether, the knowledge of ACE2 receptor, viral S glycoproteins and cellular proteases required for the cell entry 
of Cov-2 may indeed provide new approaches to the treatment of COVID-19, four of them listed below:

1. Receptor-binding domain (RBD) of S-glycoprotein of $\mathrm{CoV}-2$ to be isolated and administered separately, thereby ligating ACE2 and saturating its available connection loci.

2. An anti-ACE2 antibody may be used or fragment of single chain antibodies (scFv) to achieve the same saturation.

3. CoV-2 to be attacked directly by using the extracellular domain of ACE2, such as a bait aimed at binding to S-glycoprotein. Fc-domain associated with ACE2 would facilitate long-term circulation in a biological environment (ACE2-Fc).

The data obtained from the RBD-docking experiments were used to map RBD-ACE-2 interactions that could be used to design small molecular inhibitors of binding site. After virtual screening of over 3000 compounds was found and already confirmed in experiments that two compounds of the anthracycline drug group (zorubicin and aclarubicin) as well as the food dye E 155 are potent RBD inhibitors of viral S-glycoproteins for ACE2 receptors $(24,25)$.

$\mathrm{CoV}-2$ life-span is illustrated in Figure 5.

\section{The Bulgarian contribution}

In the same direction are the attempts to use antibodies in the sera of infected people or administration of monoclonal antibodies to neutralize $\mathrm{CoV}-2$. Such a therapeutic approach is currently being intensively developed in Center of Antibody Therapeutics, University of Pittsburgh Medical School, Pittsburgh, PA, USA, in which leading participant is one of the most prominent Bulgarian molecular biologists Dimitar S. Dimitrov (26).

\section{OTHER POTENTIAL THERAPEUTIC APPROACHES}

\section{III.1. ACE inhibitors as antiviral agents}

Widely used ACE inhibitors (captopril, enalaprilat, lisinopril), drugs regulating Ang II levels, and, respectively, vascular tone, were associated with the ACE2's catalytic center. It would be important to show whether these enzyme inhibitors can indirectly change the conformation of the site of viral RBD and thus affect the interaction of ACE2 with CoV-2. It is certainly useful to test these drugs for their ability to block RBD-ACE2 interaction (27). Useful information on this issue would be the monitoring of the level of antiviral protection of the thousands of heart patients taking ACE inhibitors as main therapy.

In the initial stages of research are substances with potential to reduce the expression of ACE2 found after analysis of

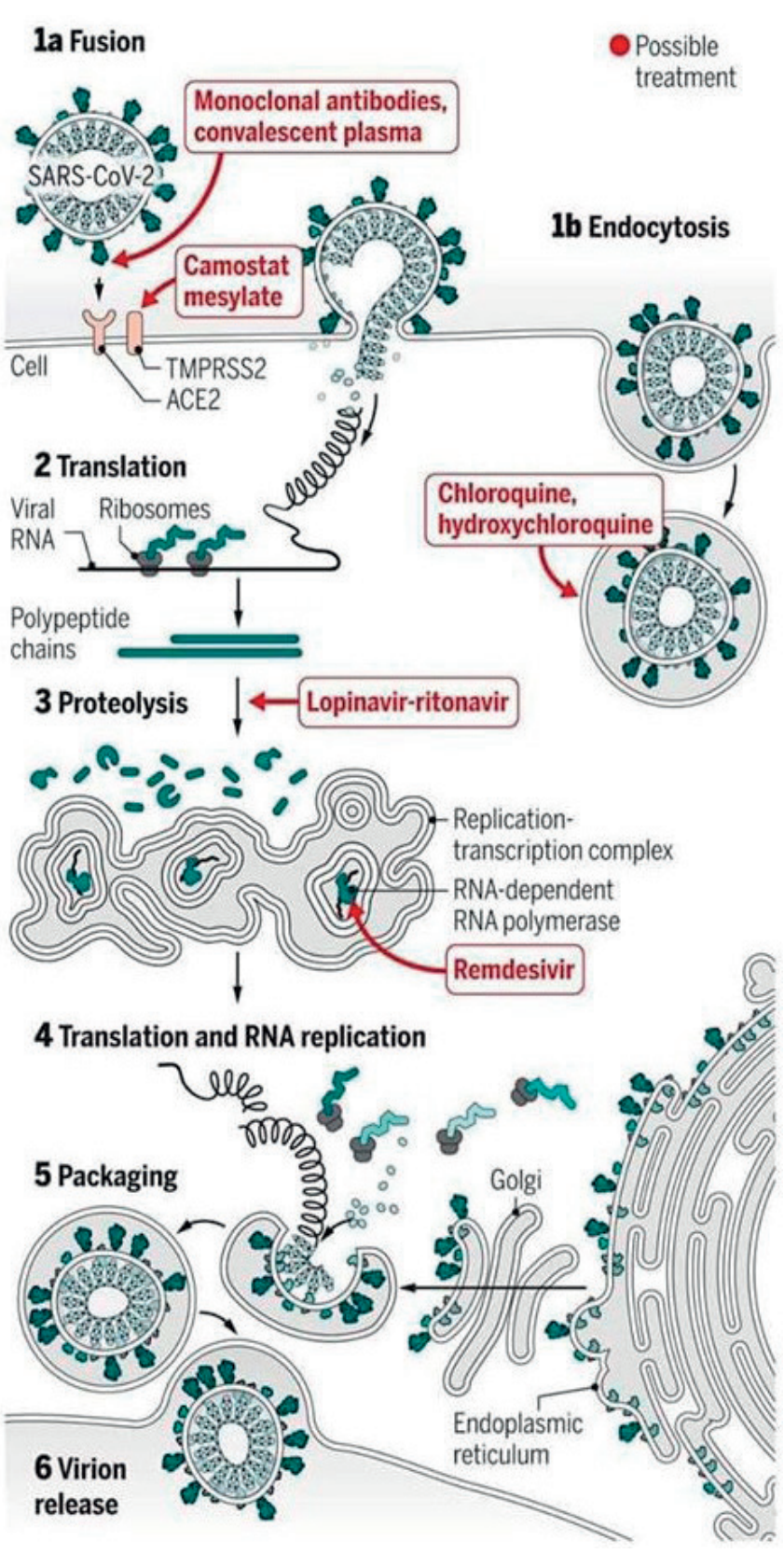

Figure 5. Schematic representation of the life cycle of $\mathrm{CoV}-2$ and the corresponding pharmacotherapeutic capabilities to respond to COVID-19. Source: the journal Science.

databases: (i) Connectivity Map (CMap) - Azathioprine, and (ii) JeaMoon Map (JMap) (traditional Chinese medicine): Andrographis, Urtica, Sambucus, Astragalus, also valproic acid, butyrate, and epoxomycin (28).

\section{III.2. Repurposed and new drugs for COVID-19}

Several of novel and repurposed therapeutics are: (i) 
Aricitinib, an approved drug for rheumatic arthritis, whose effectiveness against $\mathrm{CoV}-2$ was detected by the methods of artificial intelligence (29), (ii) Biologicals, human monoclonal antibodies against different pro-inflammatory cytokines; examples: Anakirna, a recombinant form of human interleukin-1 receptor antagonist (IL-1RA) repurposed for COVID-19 treatment, because IL-1 is one of the key pro-inflammatory cytokines involved in the development of cytokine release syndrome, Tocilizumab (trade name Actemra), humanized monoclonal antibody against interleukin-6 receptor (IL-6R), an immunosuppressive drug for the treatment of rheumatoid arthritis (30), Meplazumab, an anti-CD147 monoclonal antibody, because CD147 is one of the CoV-2 receptors (as mentioned above, at the section I.1.), (iii) Lycorine, an alkaloid present in high concentrations together with galantamine in the native endemic "swamp" snowdrop Leucojum aestivum (Amaryllidaceae), was reported to express highly antiviral activity $(\mathrm{EC} 50=1.63 \mu \mathrm{M})$ against MERS-CoV, while protecting BALB/c mice against mortality from $\mathrm{HCoV}-\mathrm{OC} 43$ by reducing viral load in the central nervous system (31); it also expresses anti-inflammatory and bronchorelaxing effect, and (iv) Colchicine, an old drug with new therapeutic applications (32); its anti-inflammatory properties against COVID-19-induced cytokine storm were appreciated recently (33 and their Refs numbered 124, 125); for Omalizumab, a recombinant DNA-derived humanized IgG1 monoclonal antibody that specifically binds to free human immunoglobulin E, see $(34,35)$.

In the same "storm", Pentoxifylline (Trental) could be another anti-cytokine drug (of low price and safety) in COVID-19. It is a methyl-xanthine derivative that inhibits phosphodiesterase IV. Pentoxifylline is known as a blood rheology improving drug prescribed in patients with peripheral artery disease. Such a rheological activity may also be beneficial in COVID-19 viewed as an oxygen-deprivation disease (see Yanev in this volume of Biomedical Reviews). Pentoxifylline also exerts other therapeutic effects, including (i) inhibition of HIV replication, and (ii) anti-inflammatory action via decreasing TNF- $\alpha$ level. Hence, it was prescribed in patients with AIDS, especially as an adjuvant therapy in combination with other drugs $(36,37)$.

\section{Mast cell stabilizers}

A key source of pro-inflammatory cytokines and chemokines in pulmonary COVID-19 is the lung mast cells. The natural flavonoid Luteolin is a potent inhibitor of these inflammatory factors released from mast cells (38). This can be a very effective approach to coup with mast cell-driven lung interstitial edema (39). Likewise, the mast cell stabilizers such as the anti-allergic drugs ketotifen and corticosteroids, also colchicine and pentoxifylline, may also be considered (40).

Indeed, mast cells are "master cells" as have been named by Stephen J. Galli, great in the field of mast cell research. These cells are renown for their secretion of multiple pro- and antiinflammatory cytokines (for mast cells secreted adipokines, see 40). For instance, adiponectin and irisin (41) could exert their potential therapeutic effects in COVID-19 especially in obesity patients which are more susceptible to develop COVID-19 severe outcome $(42,43)$ - that should also be kept in curious minds.

Aptamers are single-stranded RNA or single-stranded DNA (ssDNA), which can bind and detect various nucleic and non-nucleic acids with high affinity and specificity (44). Some of newly developed DNA/RNA aptamers are used also with success as therapeutic resource, for example, blocking SARS-Cov helicase, which is absolutely necessary for viral replication (45).

\section{III.3. Diet, nutrition, selenium and zinc and coronavirus}

It is not surprising that traces of zinc in patients with COVID -19 were not found (1). The state of zinc homeostasis in the body is reflected at least of two mechanisms of the development of viral infection: (i) ACE2 is a metalloenzyme with one zinc atom to one of protein chains. The intake of zinc through food or synthetic agents ( $20 \mathrm{mg}$ daily) during and after treatment would have an incentive effect for faster recovery of the organism (27), and (ii) there is evidence that facilitating cell penetration of extracellular zinc from certain substances (ionophores), such as pyrithione and chloroquine, in low concentrations inhibit viral RNA-dependent SARS-CoV RNA polymerase $(46,47)$, and (ii) a recent study shows that in the protein envelope of virus itself there is a labile bound zinc to cysteine, involved in maintaining the structure of the viral envelope. This implies the testing of $\mathrm{Zn}$-binding preparations as a means of the destruction of $\mathrm{CoV}-2$ power. Accordingly, the combined administration of Disulfiram and Interferon leads to encouraging results in CoV-2-infected patients (48).

Omega-3 fatty acids, especially eicosapentaenoic acid and docosahexaenoic acid, exert anti-inflammatory effects that may benefit COVI-19 patients (43) These latter data open a discussion on the therapeutic potentials of specialized pro- 
resolving lipid mediators, such as resolvins, protectins, etc.

Selenium is also recommended as an important factor in the antioxidant protection (100 mcg daily) in COVID-19 (49).

Vitamin C in daily doses of $3000 \mathrm{mg}$, taken separately, also exerts a positive effect (50).

Vitamin D (51) and polyphenols (52) supplementation may, by stimulating expression of the neurotrophin nerve growth factor (NGF), bring preventive and curable benefits, also for brain disorders in COVID-19 as well as post-COVID syndrome (see Kostov's Dance Round in this volume of Biomedical Reviews).

\section{FINAL MESSAGE}

We reason the described novel and repurposed therapeutic approaches could lead to the identification of better drugs for COVID-19. And hope that the present Dance Round COVID-19 provides information and knowledge of the opportunity of modern pharmacology and biotechnology to cope with CoV-2 infection. This may provoke the world scientific community to share (not commercialize) all the available scientific data to achieve overall success. Because we believe that the dissemination-of-knowledge (DOK) is an essential component of basic, clinical and translational biomedical research also in COVID-19 and post-COVID syndrome.

\section{CONFLICT OF INTEREST}

The authors declare no conflicts of interest exist.

\section{ACKNOWLEDGEMENTS}

We thank your brain-and-heart friends (BHF) for the valuable discussions.

\section{REFERENCES}

1. Zhang L, Liu Y. Potential interventions for novel coronavirus in China: A systematic review. J Med Virol 2020; 92(5): 479-490. [DOI: 10.1002/jmv.25707]

2. Shen L, Niu J, Wang C, Huang B, Wang W, Zhu N, et al. High-Throughput Screening and Identification of Potent Broad-Spectrum Inhibitors of Coronaviruses. J Virol 2019; 93(12): e00023-00019. [DOI: 10.1128/JVI.00023-19]

3. Dimitrov DC. HIV-1 infection of cells and AIDS progression. Biomed Rev 1993;2:1-8.

4. Chaldakov GN. Intracellular fusogens and antifusogens in HIV-1-CD4 mediated membrane fusion? Biomed Rev $1993 ; 2(79-80)$.
5. Chaldakov GN. Inhibition of receptor-mediated cellular entry of viruses including HIV: a perspective on further researches on chemotherapy in viral diseases including AIDS. Med Hypotheses 1990; 33(4): 265-268. [DOI: 10.1016/0306-9877(90)90140-a]

6. Shiryaev SA, Remacle AG, Ratnikov BI, Nelson NA, Savinov AY, Wei G, et al. Targeting host cell furin proprotein convertases as a therapeutic strategy against bacterial toxins and viral pathogens. $J$ Biol Chem 2007; 282(29): 20847-20853. [DOI: 10.1074/jbc. M703847200]

7. Chaldakov G, Yanev S. RME-based pharmacology: the inhibition of viral entry as therapeutic perspective in viral diseases including aids. hypothesis updated and enlarged. Biomed Rev 2018; 29:109-118.

8. Li G, De Clercq E. Therapeutic options for the 2019 novel coronavirus (2019-nCoV). Nat Rev Drug Disc 2020; 19:149-150. [DOI: 10.1038/d41573-020-00016-0]

9. Chen Y, Guo Y, Pan Y, Zhao ZJ. Structure analysis of the receptor binding of 2019-nCoV. Biochem Biophys Res Commun 2020. [DOI: 10.1016/j.bbrc.2020.02.071]

10. Wu Y. Compensation of ACE2 Function for Possible Clinical Management of 2019-nCoV-Induced Acute Lung Injury. Virol Sinica 2020. [DOI: 10.1007/s12250-02000205-6]

11. Imai Y, Kuba K, Ohto-Nakanishi T, Penninger JM. Angiotensin-Converting Enzyme 2 (ACE2) in Disease Pathogenesis. Circ J 2010; 74(3): 405-410. [DOI: 10.1253/circj.CJ-10-0045]

12. Ferrario CM. ACE2: more of Ang-(1-7) or less Ang II? Curr Opin Nephrol Hypertens 2011; 20(1): 1-6. [DOI: 10.1097/MNH.0b013e3283406f57]

13. Liu Y, Yang Y, Zhang C, Huang F, Wang F, Yuan J, et al. Clinical and biochemical indexes from 2019-nCoV infected patients linked to viral loads and lung injury. Sci China Life Sci 2020; 63(3): 364-374. [DOI: 10.1007/ s11427-020-1643-8]

14. Cao Y, Li L, Feng Z, Wan S, Huang P, Sun X, et al. Comparative genetic analysis of the novel coronavirus (2019-nCoV/SARS-CoV-2) receptor ACE2 in different populations. Cell Disc 2020; 6(1): 11. [DOI: 10.1038/ s41421-020-0147-1]

15. Zhao Y, Zhao Z, Wang Y, Zhou Y, Ma Y, Zuo W. Singlecell RNA expression profiling of ACE2, the putative receptor of Wuhan 2019-nCov. bioRxiv 2020. [DOI: 10.1101/2020.01.26.919985] 
16. Wang J, Luo Q, Chen R, Chen T, Li J. Susceptibility Analysis of COVID-19 in Smokers Based on ACE2. Preprints 2020 2020; v1(2020030078). [DOI: 10.20944/ preprints202003.0078.v1]

17. Chaldakov GN. Principles of Cell and Tissue Biology. Textbook for students and all curious minds in biomedicine (In press).

18. Kearney J. Chloroquine as a Potential Treatment and Prevention Measure for the 2019 Novel Coronavirus: A Review. Preprints 2020, 2020030275 2020. [DOI: 10.20944/preprints202003.0275.v1]

19. Al-Bari MAA. Targeting endosomal acidification by chloroquine analogs as a promising strategy for the treatment of emerging viral diseases. Pharmacol Res Persp 2017; 5(1): e00293-e00293. [DOI: 10.1002/prp2.293]

20. Wang M, Cao R, Zhang L, Yang X, Liu J, Xu M, et al. Remdesivir and chloroquine effectively inhibit the recently emerged novel coronavirus $(2019-\mathrm{nCoV})$ in vitro. Cell Res 2020; 30(3): 269-271. [DOI: 10.1038/ s41422-020-0282-0]

21. Cortegiani A, Ingoglia G, Ippolito M, Giarratano A, Einav S. A systematic review on the efficacy and safety of chloroquine for the treatment of COVID-19. J Crit Care 2020. [DOI: 10.1016/j.jcrc.2020.03.005]

22. Hoffmann M, Kleine-Weber H, Schroeder S, Kruger N, Herrler T, Erichsen S, et al. SARS-CoV-2 Cell Entry Depends on ACE2 and TMPRSS2 and Is Blocked by a Clinically Proven Protease Inhibitor. Cell 2020. [DOI: 10.1016/j.cell.2020.02.052]

23. Jin Z, Smith LK, Rajwanshi VK, Kim B, Deval J. The Ambiguous Base-Pairing and High Substrate Efficiency of T-705 (Favipiravir) Ribofuranosyl 5'-Triphosphate towards Influenza A Virus Polymerase. PLOS ONE 2013; 8(7): e68347. [DOI: 10.1371/journal.pone.0068347]

24. Senathilake K, Samarakoon S, Tennekoon K. Virtual Screening of Inhibitors Against Spike Glycoprotein of 2019 Novel Corona Virus: A Drug Repurposing Approach. Preprints 2020, 2020030042 2020. [DOI: 10.20944/preprints202003.0042.v1]

25. Kruse RL. Therapeutic strategies in an outbreak scenario to treat the novel coronavirus originating in Wuhan, China. F1000 Res 2020; 9:72-72. [DOI: 10.12688/ f1000research.22211.2]

26. Wang L, Xu J, Kong Y, Liang R, Li W, Li J, et al. Engineering a Novel Antibody-Peptide Bispecific Fusion
Protein Against MERS-CoV. Antibodies (Basel) 2019; 8(4). [DOI: 10.3390/antib8040053]

27. Guy JL, Jackson RM, Acharya KR, Sturrock ED, Hooper NM, Turner AJ. Angiotensin-Converting Enzyme-2 (ACE2): Comparative Modeling of the Active Site, Specificity Requirements, and Chloride Dependence. Biochemistry 2003; 42(45): 13185-13192. [DOI: 10.1021/ bi035268s]

28. Cui Q, Huang C, Ji X, Zhang W, Zhang F, Wang L. Possible Inhibitors of ACE2, the Receptor of 2019nCoV. Preprints 2020 2020; v1([DOI: 10.20944/preprints202002.0047.v1]

29. Richardson P, Griffin I, Tucker C, Smith D, Oechsle $\mathrm{O}$, Phelan A, et al. Baricitinib as potential treatment for 2019-nCoV acute respiratory disease. Lancet 2020; 395(10223): e30-e31. [DOI: 10.1016/S01406736(20)30304-4]

30. Ohsugi Y. The immunobiology of humanized Anti-IL6 receptor antibody: From basic research to breakthrough medicine. J Transl Autoimmun 2020; 3(100030. [DOI: 10.1016/j.jtauto.2019.100030]

31. Pillaiyar T, Meenakshisundaram S, Manickam M. Recent discovery and development of inhibitors targeting coronaviruses. Drug Discovery Today 2020. [DOI: 10.1016/j. drudis.2020.01.015]

32. Chaldakov GN. Colchicine, a microtubule-disassembling drug, in the therapy of cardiovascular diseases. Cell Biol Int 2018;42(8):1079-1084. [DOI:10.1002/cbin.10988]

33. Zubiaur P, Koller D, Saiz-Rodríguez M, Navares-Gómez M, Abad-Santos F. Important Pharmacogenetic Information for Drugs Prescribed During the SARS-CoV-2 Infection (COVID-19). Clin Transl Sci 2020; 13(6): 1023-1033. [DOI: https://doi.org/10.1111/cts.12866]

34. Yalcin AD, Yalcin AN. Future perspective: biologic agents in patients with severe COVID-19. Immunopharmacol Immunotoxicol 2021; 43(1): 1-7. [DOI: 10.1080/08923973.2020.1818770]

35. Zhao M. Cytokine storm and immunomodulatory therapy in COVID-19: Role of chloroquine and antiIL-6 monoclonal antibodies. Int $J$ Antimicrol Agents 2020; 55(6): 105982-105982. [DOI: 10.1016/j.ijantimicag.2020.105982]

36. Chaldakov GN. An antitumour necrosis factor therapy. AIDS 1992;6(4):439-400. PMID: 1616647 
37. Seirafianpour F, Mozafarpoor S, Fattahi N, Sadeghzadeh-Bazargan A, Hanifiha M, Goodarzi A.Treatment of COVID-19 with pentoxifylline: Could it be a potential adjuvant therapy? Dermatol Ther 2020;33(4):e13733. [DOI: 10.1111/dth.13733]

38. Theoharides TC. Potential Association of Mast Cells with COVID-19. Ann Aller Asthma Immunol 2020: S1081-1206(1020)31165-31160. [DOI: $10.1016 / \mathrm{j}$. anai.2020.11.003]

39. Motta Jr S, Miggiolaro AFR, Nagashima S, de Paula CBV, Baena CP, Scharfstein J, et al. Mast Cells in Alveolar Septa of COVID-19 Patients: A Pathogenic Pathway That May Link Interstitial Edema to Immunothrombosis. Front Immunol 2020; 11(2369). [DOI: 10.3389/ fimmu.2020.574862]

40. Chaldakov GN, Tonchev AB, Tuncel N, Atanassova P, Aloe L. Adipose tissue and mast cells. Adipokines as Yin-Yang modulators of inflammation. In: Nutrition and Health: Adipose Tissue and Adipokines in Health and Disease. Editors: G. Fantuzzi and T. Mazzone. Humana Press Inc., Totowa, NJ. 2007; pp 151-158.

41. Chaldakov GN, Aloe L, Özturk L, Pancheva R, Fiore M, Yanev S, Tonchev AB. Chapter 5. Adipokines and myokines (adipomyokines) in diabetes and related cardiometabolic diseases: A (un)expected alliance. In: Gumpeny R. Sridhar, editor. Advances in Diabetes. (In press)

42. de Oliveira M, De Sibio MT, Mathias LS, Rodrigues BM, Sakalem ME, Nogueira CR. Irisin modulates genes associated with severe coronavirus disease (COVID-19) outcome in human subcutaneous adipocytes cell culture. Mol Cell Endocrinol 2020;515:110917. [DOI: 10.1016/j. mce.2020.110917].

43. Messina G, Polito R, Monda V, Cipolloni L, Di Nunno N, Di Mizio G, Murabito P, et al. Functional role of dietary intervention to improve the outcome of COVID-19: A hypothesis of work. Int J Mol Sci 2020; 21:3104.

44. Torabi R, Ranjbar R, Halaji M, Heiat M. Aptamers, the bivalent agents as probes and therapies for coronavirus infections: A systematic review. Mol Cell Probes 2020; 53(101636. [DOI: https://doi.org/10.1016/j. mcp.2020.101636]

45. Shum KT, Tanner JA. Differential Inhibitory Activities and Stabilisation of DNA Aptamers against the SARS Coronavirus Helicase. ChemBioChem 2008; 9(18): 3037 3045. [DOI: https://doi.org/10.1002/cbic.200800491]

46. Velthuis AJW, van den Worm SHE, Sims AC, Baric RS, Snijder EJ, van Hemert MJ. Zn2+ Inhibits Coronavirus and Arterivirus RNA Polymerase Activity In Vitro and Zinc Ionophores Block the Replication of These Viruses in Cell Culture. PLOS Pathogens 2010; 6(11): e1001176. [DOI: 10.1371/journal.ppat.1001176]

47. Xue J, Moyer A, Peng B, Wu J, Hannafon BN, Ding W-Q. Chloroquine is a Zinc Ionophore. PLOS ONE 2014; 9(10): e109180. [DOI: 10.1371/journal.pone.0109180]

48. Sargsyan K, Chen T, Grauffel C, Lim C. Identifying COVID-19 Drug-Sites Susceptible to Clinically Safe Zn-ejector Drugs Using Evolutionary/Physical Principles. Preprints 2020, 20200300`12 2020.

49. Steinbrenner H, Al-Quraishy S, Dkhil MA, Wunderlich F, Sies H. Dietary Selenium in Adjuvant Therapy of Viral and Bacterial Infections. Adv Nutr 2015; 6(1): 73-82. [DOI: 10.3945/an.114.007575]

50. Colunga Biancatelli RML, Berrill M, Marik PE. The antiviral properties of vitamin C. Expert Rev Anti-infect Ther 2020; 18(2): 99-101. [DOI: 10.1080/14787210.2020.1706483]

51. Xu Yi, Baylink DJ, Chen C-S, Reeves ME, Xiao J, Lacy C, et al. The importance of vitamin D metabolism as a potential prophylactic, immunoregulatory and neuroprotective treatment for COVID-19. J Transl Med 2020;18(1):322 [DOI: 10.1186/s12967-020-02488-5]

52. Carito V, Ceccanti M, Tarani L, Ferraguti G, Chaldakov GN, Fiore M. Neurotrophins' modulation by olive polyphenols. Curr Med Chem 2016; 23:3189-3197. [PMID: 27356540] 